\title{
Uma introdução à história econômica ${ }^{1}$
}

\section{Igor Zanoni Constant Carneiro Leão ${ }^{2}$ \\ Anna Luiza Barbosa Dias de Carvalho ${ }^{3}$}

\begin{abstract}
Resumo
Este texto é um pequeno ensaio acerca do estudo e do exercício da história econômica, especialmente visando aos estudantes dos primeiros anos dos cursos de economia. Seu objetivo é contribuir para a compreensão de uma área difícil da economia na qual, no Brasil, tivemos poucos, mas grandes mestres, como Caio Prado Jr. e Celso Furtado. Começa-se por uma discussão das próprias áreas mais consagradas do pensamento econômico para deter-se na contribuição do pensamento marxista na reflexão sobre a história econômica. Finalmente, fazem-se algumas considerações sobre a formação econômica brasileira e sua atualidade de molde a estimular o debate.
\end{abstract}

Palavras-chave: História econômica; Pensamento econômico.

\begin{abstract}
An introduction of economic history

This text is a small essay about the study and the practic of the Economic History, specially aiming the students in the first years of the Economics courses. Its objective is a contribution to the understanding of a difficult area of Economics, but where in Brazil we have had few but great masters such as Caio Prado Jr. and Celso Furtado. We begin by a discussion of its areas consecrated to the Economic Thinking to detain ourselves in the contribution of the Marxist thinking in a reflection about Economic History. Finally, we make some considerations about the economic formation in Brazil and its actuality in a way to stimulate the debate.
\end{abstract}

Key words: Economic history; Economic thought.

JEL N01.

Ao iniciar seu curso de economia, o aluno, em geral, se vê em dificuldades para localizar o objeto da história econômica. Essa dificuldade se dá porque, nos livros-texto de teoria microeconômica, introdução à economia e, mesmo eventualmente, nos de história do pensamento econômico, se dá uma definição essencialmente anti-histórica de economia.

Como se sabe, a definição dominante de economia é a de uma ciência de maximização das utilidades de uma dada população, dada uma dotação de recursos escassa, pelo menos para que todas as utilidades possam ser atendidas. Com um método matemático pelo qual são determinados, ao mesmo tempo, o consumo, a produção, a distribuição de rendimentos, essa ciência é basicamente calcada no cálculo diferencial e integral a partir de algumas constantes, como o tamanho da população, seus gostos, a distribuição de recursos e a tecnologia. Dessa forma, chega-se a um resultado lógico que

(1) Trabalho recebido em agosto de 2007 e aprovado em dezembro de 2007.

(2) Professor do Departamento de Economia da Universidade Federal do Paraná (UFPR), Curitiba, PR, Brasil. E-mail: igorzaleao@ yahoo.com.br.

(3) Professora do Departamento de Economia da Universidade Federal do Paraná (UFPR), Curitiba, PR, Brasil. E-mail: annalubd@ig.com.br.

Economia e Sociedade, Campinas, v. 17, n. 3 (34), p. 539-548, dez. 2008. 
depende dessas constantes e, nesse sentido, o método é estático. Os resultados só mudarão se os parâmetros utilizados mudarem, daí se ter uma transição de uma posição estática para outra, e o método recebe com propriedade o nome de estática comparativa.

Essa definição de economia é anti-histórica porque não se leva em conta o que motivou os parâmetros a serem o que são. Por exemplo, não se sabe por que a tecnologia existente veio a ser o que é, nem se fala na dinâmica da população; os gostos também são inexplicáveis, a estrutura econômica parece solidificar-se a partir de nada no ambiente. Também não há uma explicação para as mudanças entre uma posição estática e outra pela própria forma como são construídas as equações. Mais importante: não há, aí, a noção de concorrência entre as empresas e, por outro lado, o rendimento na margem de cada fator de produção; por exemplo, o trabalho é igual à sua contribuição na margem ao produto, de forma que a teoria tem, em si, uma noção de justiça distributiva, independentemente de não explicar a distribuição original de recursos.

Essa visão da economia como a ciência da escassez foi criticada internamente pelo economista austríaco Joseph Schumpeter, já no início do século XX, em seu livro Teoria do Desenvolvimento Econômico. Após explicar a visão convencional de economia, sua beleza temporal e logicamente coerente, Schumpeter introduz dois conceitos que revolucionarão a visão corrente de economia. O primeiro é a noção de concorrência. Agindo no interior dos mercados e impulsionando mudanças na organização das firmas, na estrutura produtiva, na tecnologia e em todos os outros aspectos relevantes aí, a concorrência tem uma força de destruição e de criação de todos os aspectos essenciais nas firmas e nos mercados, sejam produtivos, sejam de consumo. Mais tarde, em Capitalismo, Socialismo e Democracia, o autor denomina esse processo de "destruição criadora" e alerta para o fato de que o importante é perceber como o capitalismo cria e destrói suas estruturas e não como as mantém ao longo do tempo.

Outro aspecto importante desse último livro é a percepção, tal qual já feita no pensamento de Marx que o antecede, de que a racionalidade capitalista penetra em outras áreas da vida humana. Nesse sentido, as relações amorosas começam a se pautar por uma lógica de lucro e de vantagem, os filhos são escolhidos em função das atividades produtivas ou outras de cada membro do casal, ao mesmo tempo em que as grandes corporações destroem o mito heróico dos grandes empresários, tão bem protagonizado por John Ford. Isso cria uma tendência à mudança social e política, dando outros aspectos de cunho histórico ao capitalismo.

Mas o capitalismo tem uma força histórica, graças, também, a um elemento ausente nas formulações convencionais, que é o poder das grandes finanças. Naquelas formulações, a moeda tinha um caráter essencialmente neutro, servindo como uma roupagem para atos econômicos que não tinham origem no próprio dinheiro. Com Schumpeter isso muda, pois ele confere um papel de destaque ao crédito criado pelos bancos e fornecido às grandes empresas, quando estas possuem aqueles elementos que estão por trás de todos os processos de destruição criadora. Esse papel inovador do dinheiro antecipa concepções acerca do dinheiro que só serão mais claramente percebidas com a Teoria Geral do Emprego, de Keynes. As concepções de Schumpeter deram origem, a partir dos anos 1980, a um forte movimento de renovação do pensamento econômico, a saber, as escolas neo-schumpeterianas e evolucionistas, da mesma forma como o pensamento keynesiano se bifurcou rumo à escola clássica ou rumo ao póskeynesianismo. 
A economia convencional nasce por volta de 1870, após aproximadamente 100 anos de domínio da chamada economia política. O ponto de partida desta é A Riqueza das Nações, de Adam Smith, em 1776. É interessante observar algumas características presentes nessa obra. Em primeiro lugar, o sentido de novidade do objeto, a economia capitalista, expresso na contraposição entre o "estado rude e primitivo que precede a apropriação privada da terra e a acumulação de riquezas", e o estado da sociedade que Smith estuda. Este tem diante de si, portanto, uma economia historicamente datada e uma economia de abundância e progresso. Além disso, Smith não apenas exalta o progresso, mas o identifica na contraposição entre homem e natureza, onde o homem aparece como ente dominante, e tal conquista do universo natural surge como algo extremamente positivo e valoroso, algo a ser aprofundado. A noção de progresso smithiana também afirma uma inversão de valores éticos que vinha se processando desde o século XVI, na qual o egoísmo e a busca racional dos próprios interesses não mais aparecem como vícios, mas sim como virtudes que levariam ao bem-estar e à felicidade de todos, na forma da sociabilidade dada em um mercado livre. O indivíduo seria livre para buscar seus interesses, e assim todos seriam livres e todos alcançariam, supostamente, a felicidade. A oposição entre os indivíduos e a oposição entre homem e natureza são estabelecidos como valores éticos legítimos.

Um outro aspecto se refere a uma certa contradição que Smith apresenta entre sua teoria do valor-trabalho e sua visão da sociabilidade mercantil.

Por um lado, Smith pensa que os interesses atuantes na troca bastam para assegurar a coesão social e eliminar qualquer intervenção política na sociedade do tipo daquelas presentes no período mercantilista. Os interesses, como disse Albert Hirschman, tomam o lugar das paixões típicas do Antigo Regime com o advento do capitalismo e criam uma sociedade que dispensa a política.

No entanto, a despeito da defesa incondicional da construção de uma sociabilidade mercantil, Smith percebe que, no momento em que a terra torna-se propriedade privada, o trabalhador deixa de desfrutar do produto integral do seu trabalho, passando a receber salário. Surgem assim interesses conflitantes, onde patrões querem pagar o mínimo possível, e trabalhadores querem ganhar o máximo possível. Smith, muito embora faça a apologia da liberdade de mercado como caminho para a satisfação dos interesses de todos, percebe que os indivíduos ocupam lugares e papéis diferenciados no mercado de trabalho, e afirma que, nas disputas com os operários, os empregadores, em geral, levam vantagem.

Por outro lado, entretanto, a teoria do valor-trabalho recoloca a política e o conflito de interesses. Ele pensa o trabalho como um labéu, um sacrifício, um esforço que o capitalista impõe ao trabalhador. Há aí um resquício da idéia bíblica do trabalho como uma pena e um castigo. O valor da mercadoria, portanto, será o trabalho comandado ou imposto sobre o trabalhador. Por esse ângulo, Smith recoloca o conflito, a história e a política em seu esquema teórico. Não por acaso chamou-se produção teórica que deriva de Smith de economia política.

Em David Ricardo, novamente, se recoloca a política de forma algo oblíqua. Para ele, o problema maior da economia política é a distribuição do produto ou do excedente. Com o avanço da acumulação, as terras na Inglaterra que forneciam o alimento básico do trabalhador, o trigo, iam sendo apropriadas até que as piores terras onde o trabalho agrícola era menos produtivo apresentassem uma produtividade menor e dessem origem a rendas 
diferenciais da terra crescentes e a um salário, em valor-trabalho, crescente, embotando a parcela do lucro que fica com o capitalista industrial. A solução para isso era abolir as Corn Laws, permitindo a importação de grãos do continente, o que era proibido graças ao poder da classe proprietária inglesa. Toda a argumentação de Ricardo gira em torno desse problema, e a economia também nasce de um problema histórico político nesse autor.

Entretanto, a oposição entre capitalista e trabalhador é colocada em segundo plano à medida que Ricardo, assim como Smith, admite a lei da população de Malthus. Segundo essa lei, o salário é regulado pela fertilidade da população, que sobe nos momentos em que o próprio salário sobe com o avanço da acumulação, mas desce em seguida pelo excesso de trabalhadores no mercado. Assim, embora admita a criação de valor pelo trabalho, o valor do trabalho e o excedente que dele se deriva são originados de causas naturais. O problema para Ricardo é menos da criação de valor pelo trabalho, e mais o trabalho como medida da produção necessária para embasar sua luta política contra os proprietários de terra.

Nesses dois autores, como percebemos, há uma visão clara do capitalismo como um sistema progressivo mas enredado nas lutas sociais do seu tempo, envolvendo antagonismos entre as classes sociais. É nesse sentido que eles fazem economia política e não, como vai denominar-se a economia convencional, meramente economia pura ou economia.

A insistência de Ricardo em que o trabalho, apesar de uma medida imperfeita do valor, era a melhor medida disponível, criou uma escola de socialistas ricardianos ligados ao movimento sindical e operário. Em grande medida, a economia convencional surge para exorcizar esses fantasmas. Um adversário do status quo muito mais temível veio na figura de Marx e seu amigo Engels, que se colocaram a um tempo como continuadores e como críticos no âmbito da economia política.

Num dos seus primeiros textos, o Manifesto Comunista, de 1948, esses autores percebem a capacidade da burguesia nascente em revolucionar a sociedade preexistente. Assim,

A burguesia historicamente teve um papel extremamente revolucionário.

A burguesia, todas as vezes em que chegou ao poder, pôs termo a todas as relações feudais, patriarcais e idílicas. Desapiedadamente, rompeu os laços feudais heterogêneos que ligavam o homem aos seus "superiores naturais" e não deixou restar vínculo algum entre um homem e outro além do interesse pessoal estéril, além do "pagamento em dinheiro" desprovido de qualquer sentimento. Afogou os êxtases mais celestiais do fervor religioso, do entusiasmo cavalheiresco nas águas geladas do calculismo egoísta. Converteu mérito pessoal em valor de troca. E no lugar das incontáveis liberdades reconhecidas e adquiridas implantou a liberdade única e sem caráter do mercado. Em uma palavra, substituiu a exploração velada por ilusões religiosas e políticas pela exploração aberta, imprudente, direta e brutal (Engels; Marx, 1998, p. 42-43).

Entre considerações desse tipo, Marx e Engels não escondem sua admiração pelo poder revolucionário e criativo do capitalismo:

A burguesia revelou como demonstração brutal de força, tão admirada pelos reacionários da Idade Média, pode encontrar seu complemento perfeito na preguiça mais indolente. Foi a primeira a dar provas do que a atividade humana pode empreender. Realizou maravilhas que superaram de longe as pirâmides egípcias, os aquedutos romanos e as catedrais góticas; 
conduziu expedições que puseram na sombra todos os êxitos anteriores de nações e cruzadas (Engels; Marx, 1998, p. 43).

Esse espírito revolucionário da burguesia, seu caráter revolucionário, a um tempo destruidor e criador, que subverte todo o existente, dissolve no ar tudo que é sólido, foi o campo de trabalho como historiador, filósofo e economista de Marx, secundado pelo "segundo violino" Engels. Já no Manifesto Comunista, encontramos uma admirável súmula do trabalho posterior de ambos, seus pontos de partida e sua visão política. Um ponto fundamental aí é a idéia de historicidade do capitalismo e a visão de que todas as sociedades são historicamente formadas e dissolvidas no interior da luta de classes.

No capitalismo, a luta de classes dominantes se trava entre proletários e burguesia, mas em todas as formações sociais há uma luta de classes envolvendo a produção material e sua distribuição. Assim, para Marx e Engels, a história de todas as sociedades existentes até então é a história da luta de classes. Poderíamos dizer que a luta de classes é a própria história. Por outro lado, essa luta se trava em vários níveis, mas há um nível dominante, que é a produção material da vida.

Esse ponto foi expresso por esses autores na Contribuição para a crítica da economia política:

$\mathrm{Na}$ produção social de sua existência, os homens estabelecem relações determinadas, necessárias, independentes de sua vontade, relações de produção que correspondem a um determinado grau de desenvolvimento das forças produtivas materiais. O conjunto dessas relações de produção constitui a estrutura econômica da sociedade, a base concreta sobre a qual se eleva uma superestrutura jurídica e política e à qual correspondem determinadas formas de consciência social. $\mathrm{O}$ modo de produção da vida material condiciona o desenvolvimento da vida social, política e intelectual em geral. Não é a consciência dos homens que determina seu ser; é o seu ser social que, inversamente, determina sua consciência. Em certo estádio de desenvolvimento, as forças produtivas materiais da sociedade entram em contradição com as relações de produção existentes ou o que é sua expressão jurídica, com as relações de propriedade no seio das quais se tinha movido até então. De forma de desenvolvimento das forças produtivas essas relações transformam-se em seu entrave. Surge então uma época de revolução social (Marx, 1989, p. 28-29).

Essa metáfora de base e superestrutura constituindo um modo de produção e tentando dar conta de sua superação foi bastante criticada por historiadores por seu acentuado esquematismo. De qualquer modo, ela privilegia a determinação em última instância dos interesses materiais na história das sociedades e suas conexões com as produções ideológicas como o direito, a religião ou a arte. Marx acentua aí já um embrião de teoria acerca de como as sociedades se estruturam e de como transcorrem historicamente até sua substituição por outra sociedade a partir de suas contradições internas.

De qualquer modo, um número muito grande de historiadores deu importância às intenções de Marx. Assim, Pierre Vilar, em Desenvolvimento Econômico e Análise Histórica, procura explicar o conceito de modo de produção como todas as relações entre o homem e seu trabalho, entre o homem e seu produto, como reações de criação recíproca, englobando as técnicas e as relações sociais, as noções de trabalho e de produto que se ligam de forma determinante a relações jurídicas, os costumes morais, intelectuais ou religiosos. O modo de produção é uma articulação entre a relação social fundamental, que procura responder quem detém a diferença e se cria entre o valor global criado pelos 
trabalhadores e o valor que estes percebem, e as forças produtivas que sintetizam toda capacidade reprodutiva do homem enquanto reproduzem sua riqueza utilizando os dons da natureza e recriando-a.

Vilar sugere que a noção de forças produtivas como relação entre trabalho e valor encarna o segredo da história social e da transformação histórica. Quando as forças produtivas se põem em movimento tudo mais se move, não apenas do ponto de vista técnico, mas também social e psicológico. Ao mesmo tempo, as relações sociais de produção e o modo de produção são fundamentais no estudo dos problemas cotidianos que se colocam ao historiador social quando este está estudando a evolução do mundo rural, o aparecimento e a libertação dos servos, a gênese do arrendatário capitalista e assim por diante. Finalmente, quando as forças produtivas se modificam os modos de produção enquanto conjuntos vastos de costumes e de estruturas simultaneamente técnicas, sociais e psicológicas também mudam, e a partir desse momento, o modo de propriedade e as relações entre classe sociais também não podem ser mantidos.

Evidentemente, esses conceitos dão conta da estrutura íntima de cada sociedade sem exaurir toda a sua historicidade. A rigor, estamos aí numa aproximação da história que evita uma visão idealista e reacionária da vida social e a percepção, como disse Marx, de que tudo o que existe merece perecer em favor de um mundo mais humano.

Embora o pensamento de Marx se arrogue ser materialista e cientificista, ele possui pressupostos éticos e de valor, distintos daqueles proclamados por Smith, que colocam a necessidade de instituir novas formas de sociabilidade humana, superando a forma de sociabilidade dada no mercado. Marx propõe uma sociedade econômica diferente, com um novo indivíduo, uma nova coletividade. Portanto, surgem, como pressuposto, novas relações não apenas entre esses ditos "novos" indivíduos, mas novas relações entre indivíduos, coletividade e natureza, que amenizem as distâncias construídas entre os homens e quebrem a lógica de dominação da natureza expressa implicitamente na noção de progresso.

Nessa linha, utilizando um texto já antigo de Hobsbawm, a força da visão marxista sempre esteve na ênfase sobre a existência da estrutura social e sua dinâmica interna de mudança. A partir daí, pode-se fazer uma crítica às teorias que reduzem a história a uma simples mudança da sociedade "tradicional" para "moderna" ou "industrial", como nas etapas do crescimento econômico de Rostow, que elimina e supersimplifica os mecanismos das mudanças históricas. Em segundo lugar, pode-se fazer uma crítica das teorias estruturalistas que também negam a historicidade, pretendendo libertar o pensamento do evolucionismo típico do século XIX. Na verdade, embora cada sociedade deva ser julgada por seus próprios padrões internos, é possível compará-las quanto a sua capacidade de controlar a natureza externa, uma vez que a questão fundamental na história é como a humanidade se desenvolveu desde o primeiro primata a usar instrumentos até hoje.

Além disso, Marx não propôs uma teoria de evolução unilinear universal, mas certos fenômenos sociais não podem aparecer na história antes de outros. Por exemplo, as economias com a dicotomia cidade-campo não podem aparecer antes das que não têm essa característica. Da mesma forma, o próprio capitalismo só pode nascer quando dissolve a co-possessão típica da exploração feudal nos pólos do capital e do trabalhador obrigado a vender sua força de trabalho num processo complexo cujas linhas centrais Marx desenhou no capítulo de $O$ Capital intitulado A Acumulação Primitiva. 
Outra observação que deve ser feita é que, em $O$ Capital, Marx se dedica, em primeiro lugar, às conexões internas do modo de produção capitalista - a mercadoria como forma elementar da riqueza na sociedade burguesa, a forma valor do produto do trabalho, a sociabilidade mercantil envolvendo o fetichismo da mercadoria e a alienação do trabalhador, a natureza intrínseca do dinheiro, a tendência a desenvolver as forças produtivas inerente ao capitalismo - e, em segundo lugar, suas leis de desenvolvimento, que envolvem não apenas transformação da lei do valor em lei de valorização do capital, mas as seguintes tendências listadas por Oskar Lange (1972):

Essas tendências seriam as seguintes: 1) $\mathrm{O}$ aumento constante da escala de produção que pela substituição da produção em pequena escala por grande escala, provocou a transição do capitalismo livremente competitivo do século XIX para a atual forma monopolista (melhor seria dizer oligopolista); 2) a substituição do laissez faire pelo intervencionismo e "planejamento"; 3) a transição do livre câmbio para o auto-protecionismo e nacionalismo econômico nas relações internacionais; 4) a constante expansão do método capitalista de produção por países não capitalistas que, enquanto a concorrência era livre, produzia pacífica saturação da economia capitalista e civilização ocidental em todo o mundo, mas que, com o capitalismo oligopolista intervencionista, provoca rivalidade imperialista entre as principais potências; 5) o agravamento da instabilidade do sistema capitalista que, ao destruir a segurança econômica e social da população dos países que o adotam, leva-os a rebelar-se contra o existente sistema econômico, qualquer que seja a ideologia, o programa em que se fundamente a rebelião (socialismo ou fascismo).

Essas leis listadas por Lange parecem ter pleno vigor ainda hoje, uma vez que o novo quadro de internacionalização produtiva e financeira não aboliu uma hierarquização do poder militar e político no mundo, antes a agravou, e que, se o socialismo teve seu espaço reduzido, o fascismo perdeu as características dos anos 1930 e 1940 para converterse no fascismo de mercado e no fundamentalismo liberal norte-americano. Por outro lado, é preciso observar que a armação teórica de Marx em $O$ Capital não significa que possamos passar desse plano teórico sem mediações à história ou mesmo à economia em qualquer país ou ponto do tempo. Muitas vezes algo semelhante a isso foi feito levando a graves incompreensões da história e da economia. Um equívoco oposto seria um historicismo que ignorasse as leis internas do modo de produção capitalista.

No caso do Brasil, esses equívocos se traduziram em forma exemplar na produção teórica dos primeiros comunistas nacionais, seguindo, aliás, a orientação da Internacional Comunista. Forjou-se um economicismo em que o desenvolvimento do país era transformado num reflexo da dominação externa e da transformação da hegemonia capitalista no mundo. Por outro lado, via-se a história nacional no quadro de uma sucessão de modos de produção europeus no Brasil. Assim, um dos problemas fundamentais do desenvolvimento brasileiro era abolir os resquícios feudais da nossa formação e promover a revolução burguesa com base no empresariado local.

Essa visão teve como contraponto o marxismo original e criativo de Caio Prado Júnior. Sem transpor rigidamente as categorias de análise marxista ao Brasil, esse autor partiu da formação colonial brasileira nos quadros da acumulação primitiva européia e forjou uma categoria, a economia colonial, que retinha as principais características dessa fase de nossa história: a heterogeneidade nacional, a desigualdade, a ausência de soberania, e outros. Contrapôs essas características, que ele mapeou e estudou num árduo esforço histórico, a uma desejada e nascente economia nacional que envolvia características opostas, e uma luta política para sua consecução num programa muito distinto do 
comunismo pensado pelo nosso Partido Comunista Brasileiro e por um teórico afamado como Nelson Werneck Sodré. Essa criatividade de Caio Prado Júnior é uma forma exemplar de fidelidade ao marxismo.

Também Celso Furtado, nosso maior economista, embora não parta de Marx, deve muito a Caio Prado na sua caracterização de um capitalismo subdesenvolvido, marcado pela não-geração de tecnologia, pobreza de massa, heterogeneidade estrutural, subordinação às grandes filiais de empresas produtivas internacionalizadas e à banca internacional. Na mesma linha caminhou Maria da Conceição Tavares, com sua ênfase nos aspectos financeiros de subdesenvolvimento e nas características do nosso capitalismo tardio e periférico. Muitos outros autores importantes se filiam mais ou menos a Marx, que sempre foi uma referência para o pensamento progressista nacional.

Fazer uma boa história econômica e social significa escrever sobre as estruturas maiores da vida de um país, ou seja, de toda a sua história. No caso do Brasil, escrever essa história é dar conta de um país que ingressou tardiamente e com grandes custos no processo de industrialização, com um empresariado que preferiu a parceria do capital estrangeiro e adotou um comportamento patrimonialista e de fragilização do Estado, onde os direitos sociais e políticos sempre foram minimizados, o que explica que cerca de 53 milhões de pessoas hoje no ano 2006 vivem em situação de pobreza. O Estado brasileiro, que perdeu suas maiores empresas na década passada, está preso nas malhas de um endividamento externo e interno que originou um parasitismo rentista sobre o orçamento público, comprometendo as políticas sociais mais gerais.

No dia 17 de março de 2006 foi fundado, no Rio de Janeiro, sob estímulo do presidente Lula, o Centro Internacional Celso Furtado de Políticas para o Desenvolvimento, ${ }^{4}$ para pensar os problemas de longo e médio prazos como inserção internacional, integração da América Latina, matriz energética, logística, emprego, distribuição de renda, combate à pobreza. Na inauguração do centro, foi lembrado que as cadeias produtivas de setores importantes da economia brasileira, inclusive o agropecuário, são controladas por empresas estrangeiras. No comércio varejista, a maior parte dos ativos é estrangeira, e $27 \%$ dos ativos bancários estão com bancos estrangeiros. O Brasil se situa no patamar onde as técnicas mais modernas chegam aos poucos sem grandes saltos, ao contrário de países que assimilam rapidamente as técnicas de produção moderna.

O investimento público é responsável por três quartos da formação bruta de capital, mas o seu compromisso com o pagamento e amortização de juros cria um problema para o crescimento do emprego e um expressivo resgate da dívida social. $\mathrm{O}$ Brasil, com 183 milhões de habitantes, concentra 80\% dessa população nas cidades, hoje com uma taxa de fertilidade de 2,1, significando que teremos uma geração grande em idade de trabalhar antes de um envelhecimento significativo da população brasileira. $\mathrm{Na}$ área da educação, 97\% das crianças de 7 a 14 anos estão na escola, mas 55\% dos alunos possuem gravíssimos problemas de interpretação de texto e uma grande maioria tem mau desempenho em matemática. A USP é a única universidade brasileira rankeada no mundo, na $196^{\mathrm{a}}$ posição.

(4) Todos os dados desta seção foram obtidos no artigo de Nelson Breve, disponível em http://agenciacartamaior.uol.com.br/templates/materiaMostrar.cfm?materia id=10329\&editoria id=7. Acesso em: 28 de março de 2006. 
Na saúde, a mortalidade infantil caiu de 52,7 para 27 crianças por mil nos últimos 25 anos, mas o Brasil tem problemas graves como o de infecção hospitalar, que inclusive vitimou o presidente Tancredo Neves. Temos 45 mil mortos no trânsito por ano para mais de 1 milhão de acidentes e a segurança pública é precária, pois o país situa-se em $4^{\circ}$ lugar em mortes violentas, com 47 mil mortes violentas por ano. Embora o Bolsa Família tenha provocado melhoria significativa no padrão de renda dos bolsões mais pobres, temos 10 milhões de empresas na informalidade, e das 5,2 milhões de empresas com CNPJ, só 1,5 milhão têm empregados.

Essas informações de diagnóstico foram feitas por economistas e sociólogos como Hélio Jaguaribe, Wilson Cano, Maria da Conceição Tavares, Carlos Lessa, Antônio Barros de Castro e Luiz Gonzaga Belluzzo. Elas indicam a dificuldade de pensar a história econômica do país ao mesmo tempo que a sua necessidade, dentro de uma armação teórica que não exclua a imaginação criadora e a vontade de refundar a nação.

Vive-se num mundo em que o homem não é sujeito de sua história, que dirá da construção da história econômica. O indivíduo tornou-se refém de uma lógica voraz de acumulação e valorização dos capitais, que faz de pessoas comuns escravas de necessidades criadas num mundo dominado pelo consumo imediatista. Todos querem ter coisas e acreditam que o ser pode, de fato, ser construído nesse ter. Tornou-se o homem escravo de coisas que ele mesmo criou e produziu. Escravo da avidez do capital de se autovalorizar e, neste sentido, fez do capitalismo um sistema para além de si mesmo que o concebeu. Na sua luta individualista e egoísta pelo progresso, o homem não foi racional e muito menos humano.

Em meio a todo esse cenário, há ainda espaço para o contraditório. Deseja-se um mundo diferente, livre das amarras em que se colocaram os seres humanos. Luta-se para pensar alternativas sociais diferentes, onde a vida seria independente das coisas. Busca-se, como neste ensaio, refletir um pouco sobre a história da economia. Mas esbarra-se nas dificuldades de um mundo de apelos introjetados nos inconscientes, como se não se pudesse existir a não ser pelas coisas que estão fora de nós e nos são estranhas. E, na maior parte das vezes, nesse processo, a contradição surge quando sucumbimos aos apelos hedonistas de consumo de tudo, até das pessoas.

É preciso, talvez, quando reflete-se sobre a história econômica, resgatar as utopias, e com elas a noção de que se precisa lutar para a superação do sistema mercantil do capital. E lutar contra o capital não é rivalizar com alguns indivíduos, mas é lutar para recuperar o que de mais humano e racional perdemos com o reinado do dinheiro: a afetividade das e nas relações humanas. Em outras palavras, de forma bem pueril, resgatar o amor. Tem-se de redescobrir a natureza humana, uma possível essência afetiva e criativa do homem, que estabeleça relações pacíficas e cooperativas não só entre os indivíduos, mas entre estes e o meio ambiente. Marx nunca quis que fôssemos contra o ser humano, mas contra aquilo que o ser humano criou: o dinheiro como fim em si mesmo, o capital, as coisas pelas coisas, o trabalho como fim em si mesmo, a voracidade do ter e do dominar.

Faz-se necessário pensar também um reordenamento entre as nações, pois o desenvolvimento capitalista recente, marcado por uma internacionalização dos negócios e das finanças sob a égide norte-americana, produziu uma polarização mundial que tem seu exemplo extremo na Guerra do Iraque e no mal-estar generalizado vinculado à violência $\mathrm{e}$ aos problemas do meio ambiente. 
Igor Zanoni Constant Carneiro Leão /Anna Luiza Barbosa Dias de Carvalgo

É preciso, portanto, repensar a própria teoria econômica e seus paradigmas. Num sentido forte, retomar o humanismo que caracterizou o liberalismo smithiano e o marxismo generoso de suas origens. Torna-se, portanto, imperativo reconfigurar as relações que os indivíduos estabelecem entre si e com a natureza. Assim, talvez se possa construir a introdução de uma nova história econômica.

\section{Bibliografia}

COLARES, Gisella. Mudança de paradigma na ciência econômica: uma percepção. Projeto de Doutorado, 2005. Mimeografado.

DOBB, Maurice. Teorias do valor e da distribuição desde Adam Smith. Lisboa: Ed. Presença, 1973.

ENGELS, Friedrich; MARX, Karl. Manifesto do Partido Comunista. São Paulo: Boitempo, 1998.

HOBSBAWM, E. J. A contribuição de Karl Marx para a historiografia. In: BLACKBURN, Robin. Ideologia na ciência social. Rio de Janeiro: Ed. Paz e Terra, 1982.

LANGE, Oskar. A economia marxista e a moderna teoria econômica. In: HOROWITZ, David (Org.). A economia moderna e o marxismo. Rio de Janeiro: Zahar Editores, 1972.

MARX, Karl. Manuscritos econômicos e filosóficos. São Paulo: Martin Claret, 2001.

1989. Contribuição para a crítica da economia política. São Paulo: Mandacaru,

RICARDO, David. Princípios de economia e tributação. São Paulo: Nova Cultural, 1996. (Coleção Os Economistas).

SCHUMPETER, Joseph. Capitalismo, socialismo e democracia. Rio de Janeiro: Zahar Editores, 1984.

SMITH, Adam. A riqueza das nações. São Paulo: Nova Cultural, 1996. (Coleção Os Pensadores).

VILAR, Pierre. Desenvolvimento econômico e análise histórica. Lisboa: Ed. Presença, 1982. 